\title{
"A Conquista da Liberdade Pelo Negro: Consenso e Contra-senso"*
}

\section{Paulo Ricardo Pezat}

Os relatos existentes acerca das relações entre escravos e senhores, em sua imensa maioria, foram escritos por indivíduos identificados com a classe senhorial, refletindo o seu ponto de vista. Devido ao baixo índice de alfabetização entre os escravos, ${ }^{1}$ são raros os documentos por eles escritos onde apareça sua percepção da realidade, o que confere um valor especial aos Processos Judiciais, pois neles constam seus depoimentos (embora transcritos por homens livres).

Nestes Processos, em geral, o negro - liberto ou cativo - aparece em condição de réu. Sendo assim, chamou-nos a atenção o processo instaurado a partir da denúncia feita à subdelegacia de Polícia da vila de São Leopoldo, no mês de novembro de 1861, segundo a qual o Capitão José Joaquim de Paula, fazendeiro daquela localidade, teria reduzido à escravidão o negro africano de nome Manoel. ${ }^{2}$ Este fato teria se dado nove anos antes (por volta de 1852), ou seja, após a promulgação da lei Eusébio de Queiróz. ${ }^{3}$

Chamado para depor, Manoel disse ser natural do Congo, na Costa da África, de idade ignorada, e que trabalhava na roça. Ao lhe perguntarem onde estava vivendo, Manoel respondeu que vivia na fazenda do capitão José Joaquim de Paula, tendo vindo da costa africana juntamente com outros companheiros, desembarcando em Tramandaí. ${ }^{4}$ Disse ainda que conseguiu fugir pouco tempo depois, com o objetivo de

\footnotetext{
* Comunicação elaborada a partir da atividade de seu autor como bolsista Pró-Reitoria de Pesquisa da Universidade Federal do Rio Grande do Sul, projeto intitulado "A História da luta anti-escravista no Rio Grande do Sul (séculos XVIII-XIX)", sob a orientaçăo da professora Margaret Bakos.
} 
alcançar a Santa Casa de Misericórdia, em Porto Alegre, para ai obter sua alforria. No caminho, Manoel diz ter conhecido o capitão Paula, que lhe indagou de sua condição, tendo, então, Manoel contado-lhe sua história e sua intenção de atingir a Santa Casa. Relata que o capitão Paula convenceu-o de que a Santa Casa não seria um bom lugar, propondo-lhe que ficasse trabalhando para ele pelo periodo de oito anos, findo o qual receberia a liberdade, assim como fazia a Santa Casa. Desde então, Manoel trabalhava na fazenda do capitão $P$ aula, de quem recebia apenas uma calça e uma camisa grossa por ano, além de algumas moedas pelo trabalho realizado aos domingos. Disse ainda "ter aquele Paula the proibido de contar a ninguém o facto pelo qual ali estava, e tão pouco arredar pé da fazenda para obter carta de alforria". Acrescentou ainda que o capitão Paula "lhe passara um papel a respeito d'elle [...] e que depositou na mão daquele preto forro José Pereira, mais que elle não sabe o que contém o papel". ${ }^{6}$ Por fim, Manoel disse que perguntara há poucos dias para o capitão Paula se ainda não havia chegado o momento de receber sua carta de alforria, ao que o capitão Paula respondeu que faltava pouco tempo.

Chamado para depor, o preto forro José Pereira declarou ser natural da costa da África, com mais de cinqüenta anos, casado e com a profissão de lavrador. Perguntado se conhecia o documento que dava ao capitão José Joaquim de Paula a faculdade de se servir da força de trabalho do negro Manoel pelo prazo de oito anos, após o qual the libertaria, o preto forro José respondeu que o conhecia porque o tinha em seu poder, tendo-lhe sido entregue por seu compadre, o capitão José Joaquim de Paula. Perguntado se sabia em que caráter estava o negro Manoel na Fazenda do capitão Paula, respondeu que se achava na condição de cativo, cumprindo o acordo firmado. Disse ainda que sabia, através do próprio Manoel, que ele havia chegado da costa da África, tendo desembarcado em Tramandaí e então fugido, com o objetivo de alcançar a Santa Casa, encontrando no caminho o capitão Paula.

O documento acima referido, que dava ao capitão Paula o direito de utilizar-se do trabalho do negro Manoel, constava dos seguintes termos:

"Digo eu Agostinho Antonio Leal, que sou senhor e possuidor de um escravo de nome Manoel Congo a cujo escravo tenho prometido dar-lhe sua liberdade, logo que 
elle me entregue a quantia de seis centos mil réis, e como o dito escravo não tem podido alcançar esta quantia, e o senhor José Joaquim de Paula a quer dar, e o escravo o quer servir, por isso me tenho convencionado com o dito senhor Paula debaixo das condições abaixo declaradas. Primeiro, que recebo da mão do senhor Paula a quantia de seis centos mil reis, com a condição de ficar liberto o dito escravo depois de servir o dito senhor Paula ou a sua familia por espaço de oito anos, sem que o dito senhor ou sua família o possão vender, ou passar a outro estranho; pois que por este tracto lhe é vedado, assim como passado dito prazo de oito annos contados da datta deste o referido escravo ipso facto forro; servindo-lhe então de Alvará, ou Carta de sua liberdade este mesmo papel de tracto; que para clareza e garantia, e a todo o tempo constar passamos três de um mesmo theor na presença das testemunhas abaixo assignadas; um que fica em meu poder, outro no do senhor Paula, e outro na mão do dito escravo Manoel. São Leopoldo desasete alias vinte e sete de maio de mil oito centos e cincoenta e seis. = Agostinho Antonio Leal $=$ José Rodrigues Cruz Vianna $=$ Manoel Coelho Ribeiro."

Este documento foi enviado para o tabelião de São Leopoldo fazer o reconhecimento de firma, mas tal não ocorreu pelo fato de que nenhum dos indivíduos que o haviam assinado eram conhecidos. O tabelião chamou atenção para o fato de que a data do contrato havia sido alterada de mil oitocentos e cinqüenta e três para mil oitocentos e cinqüenta e seis.

Em correspondência dirigida ao Chefe de Polícia da Província, o subdelegado de São Leopoldo ressalta que o mencionado contrato, supostamente escrito por Agostinho Antonio Leal, foi escrito pela mão de José Joaquim de Paula, ainda que com letra disfarçada. Também as assinaturas teriam sido feitas pela mesma mão. Chamava a atenção para o fato de as assinaturas terem sido feitas com tintas de cores diferentes daquela com a qual se redigira o contrato, o que seria uma evidência de irregularidade, pois as testemunhas deveriam estar presentes no momento em que era redigido. Reafirmava ainda a adulteração existente na data. Acrescentava que o capitão Paula estava empenhando seu voto e de seus companheiros para conquistar protetores. O subdelegado de São Leopoldo concluía a correspondência com o Chefe de Polícia da Província 
pedindo-lhe que levasse pessoalmente a apuração do caso até o fim, pois seria necessária.

"[...] uma auctoridade forte, enérgica e bem illustrada, como he Vossa Excelencia, afim de não se deixar faccinar por contos arabicos, contos de sereas e promessas capciosas; por que os habitantes do lugar e quantos desejão e amão a prosperidade moral de um paiz estarão com os olhos fitos para enxergar o desfecho deste tão importante negócio, em que foi sacrificada a liberdade de um indivíduo á paixão torpe e ambiciosa de um homem sem honra, sem moral e sem religião, visto que tudo isto sacrificou á aquella, menos presando a lei que considerou livre todos os africanos importados por contrabando. [...] Eu entendo [...] que o preto Manoel é livre de direito, mas não de facto."

Por sua vez, o Chefe de Polícia da Província escreveu ao Vice-Presidente da Província, Comendador Patrício Corrêa da Câmara, pedindo "esclarecimento sobre o logar onde deve ser recolhido esse Africano, que actualmente mandei deter no Quartel do Corpo policial". ."

José Joaquim de Paula, acusado de haver reduzido o negro Manoel à escravidão, foi chamado para prestar depoimento em Porto Alegre, na presença do Chefe de Polícia da Província, Dario Rafael Callado. Paula disse ser natural da vila do Conde, em Portugal, tendo cinqüenta e oito anos de idade e residindo no município de São Leopoldo. Perguntado pela forma como havia conhecido o africano Manoel, respondeu que, a cerca de oito anos, estando na fazenda de Bernardino José de Sena, já falecido, apareceu Manoel "dizendo que vinha fugido de cima da serra, por ser seo senhor Agostinho muito máo"; ${ }^{10}$ Bernardino teria se proposto a entrar em contato com Agostinho, a quem conheceria, com a intenção de intermediar a compra de Manoel, acertando-se o preço deste em seiscentos mil réis. Segundo Paula, foram feitas três cópias do documento, ficando uma com Agostinho, outra com ele próprio e uma terceira com o preto forro José, padrinho de Manoel. O contrato teria sido firmado em maio de 1853, portanto a mais de oito anos (depois dos quais Manoel deveria ter recebido sua liberdade), visto que o depoimento foi prestado em novembro de 1861. Perguntado pela maneira como havia sido alterada na data o título de aquisição do negro Manoel, o capitão 
Paula respondeu que ignorava a existência de tal emenda porque nunca mais vira a cópia que havia entregue ao preto forro José (que além de "compadre" do capitão Paula, era "padrinho" de Manoel).

Por fim, o inquérito menciona que as autoridades ordenaram a Paula para que apresentasse a cópia do documento que tinha em seu poder. Paula argumentou que o havia perdido no justo momento em que se dirigia para Porto Alegre, onde o entregaria às autoridades. Apresentou como "prova" da perda do documento, um anúncio por ele publicado nos jornais da capital, onde oferecia uma recompensa para quem lhe devolvesse o referido documento, acrescentando que ninguém o havia procurado para isso.

Feito este relato do conteúdo do inquérito, desejo levantar algumas questões que podem nos auxiliar na compreensão da postura adotada pelo negro Manoel, que, num primeiro momento, parece absurda.

Como já foi colocado, a lei Eusébio de Queirós, de setembro de 1850, estabeleceu medidas de combate ao tráfico inter-atlântico de escravos, considerando livres todos os africanos que entrassem a partir de então no Brasil. Assim sendo, o negro Manoel, desembarcado em Tramandaí, no início de 1852, era juridicamente livre. Como explicar então, que ele, após ter conseguido fugir dos traficantes (procurando atingir a Santa Casa de Misericórdia), aceitasse tornar-se escravo do capitão Paula?

Em geral, no contexto do Império, o negro era juridicamente escravo, lutando para tecer espaços de autonomia e afirmação de sua individualidade. Manoel, pelo contrário, era juridicamente livre, mas aceitou abrir mão desta condição, embora temporariamente.

Talvez esta atitude seja melhor compreendida se analisarmos as perspectivas existentes para um negro livre na sociedade brasileira de meados do século XIX.

Apesar da sociedade brasileira estar, naquele momento, apoiada numa organização escravista da produção, a Carta Outorgada de 1824 sequer mencionou os escravos, mesmo representando estes quase a metade da população. ${ }^{11}$ Os direitos civis eram exclusivos dos homens livres, mas não eram iguais para todos, variando segundo a situação sócio-econômica, a idade, a cor e o grau de instrução do "cidadão". Os negros estavam, em princípio, excluídos do direito de cidadania, fossem 
escravos ou forros, ${ }^{12}$ pois no regime escravocrata o escravo é, antes de mais nada, um meio de produção, passível de venda, aluguel, penhora etc.

Antes de 1872, o negro era escravo a priori, a menos que provasse 0 contrário. Exemplo disso é um decreto Imperial de 1859, que regulamentou o uso de uma classe de propriedade não reclamada, conhecida como "bens de evento", bens esses definidos como "escravos, gado ou bestas, achados sem se saber do senhor ou dono a quem pertençam". ${ }^{13}$ Tais homens e animais deveriam ser avaliados e leiloados caso seus donos não respondessem aos editais públicos.

Em 1872, a situação se alterou. A partir de então, todos os escravos deveriam ser registrados por seus donos, tornando-se livres aqueles que não estivessem matriculados. Ao longo do Império, a legislação regulamentadora do tráfico e das relações entre senhores e escravos proliferou bastante, revelando o projeto imperial de emancipação lenta e gradual do cativo, de forma a se evitar a desorganização da produção. Visava-se a emancipação do escravo, mas não a do trabalhador, 0 surgimento de uma classe de assalariados, não a extensão da cidadania. ${ }^{14}$

No Rio Grande do Sul, a questão da cidadania negra se colocou pela primeira vez no contexto da Revolução Farroupilha. Com o objetivo de arregimentar soldados para suas fileiras, os chefes farroupilhas alforriaram os escravos que se dispuseram a lutar contra o Império. Mas o liberto não poderia candidatar-se à Assembléia Constituinte e Legislativa. No projeto de constituição da República rio-grandense são considerados como cidadãos apenas os homens livres nascidos em território da República, não sendo mencionado no projeto o caso dos libertos. ${ }^{15}$

Segundo Spencer Leitman, uma das razões que retardaram 0 desfecho do conflito entre Farrapos e o Império foi o problema do destino a ser dado aos negros libertos. A solução viria com a "Surpresa dos Porongos", batalha planejada entre Caxias e Canabarro que exterminou a maior parte dos ex-escravos convertidos em soldados. Os sobreviventes teriam sido enviados para o Rio de Janeiro, tornando-se escravos da nação. ${ }^{16} \mathrm{~A}$ lei provincial de 1846 impedia que negros, mesmo sendo libertos, freqüentassem escolas primárias, o que desmascara o tão propalado igualitarismo dos farroupilhas.

Percebe-se então que a conquista da cidadania pelo negro, mesmo sendo liberto, era bastante difícil no contexto da sociedade escravista brasileira de meados do século XIX. 
A lei Eusébio de Queirós determinava que os africanos entrados no país, a partir da data de sua promulgação, seriam considerados livres, devendo ser enviados de volta para a África, mas o alcance desta lei foi bastante limitado. ${ }^{17}$

Assim sendo, Manoel tinha poucas possibilidades de voltar para sua terra de origem, restando-lhe a alternativa de iniciar uma nova vida aqui. A condição de negro, mesmo sendo juridicamente livre, inviabilizava que Manoel se apresentasse diante da sociedade escravista brasileira de uma forma autônoma. Necessitava desenvolver relações de compadrio ou de submissão com um homem livre que fosse reconhecido socialmente. Como nos revela o referido inquérito, haviam vínculos desse tipo envolvendo Manoel, o negro forro José e o capitão Paula. José servia de mediador entre os dois, pois era "padrinho" de Manoel e "compadre" do capitão Paula. Como nota Emília Viotti da Costa, as relações de apadrinhamento encobrem, sob o manto da amizade, relações de poder. ${ }^{18}$

Para melhor compreendermos o acordo estabelecido entre o negro Manoel e o capitão Paula, devemos considerar as outras opções que Manoel teria, tendo em vista que o retorno para a África parecia estar fora de questão.

A Santa Casa de Misericórdia, para onde Manoel se dirigia após ter conseguido fugir dos traficantes, recolhia crianças negras abandonadas e a população miserável de um modo geral, como os escravos moribundos alforriados por seus senhores. Na prática, as condições de vida dos negros vinculados à Santa Casa eram típicas do escravismo, sendo apenas mais disfarçadas.

Outra possibilidade seria a fuga e aquilombamento, mas devemos lembrar que Manoel estava em um meio social e geográfico que lhe era totalmente desconhecido.

O decreto $\mathrm{n}^{\mathrm{0}} 1303$, de 28/12/1853, "declara que os africanos livres cujos serviços foram arrematados por particulares, ficam emancipados depois de quatorze anos, quando o requeiram, e providencia sobre o destino dos mesmos africanos". ${ }^{19}$ Como se vê, mesmo sendo "livre", o negro permanecia impossibilitado de dispor de sua pessoa da maneira que lhe parecesse melhor. O Decreto nã 3.310, de setembro de 1864, concedeu a emancipação para todos os africanos livres existentes no Império, mas visava, antes de mais nada, transformá-los em soldados, diante da perspectiva de um conflito com o Paraguai. ${ }^{20}$ 
Assim, a escravização por um período pré-fixado apresentou-se a Manoel como uma alternativa viável no sentido de the possibilitar uma integração na sociedade brasileira. Seu relato nos permite perceber que ele tinha uma economia privada, ${ }^{21}$ ou seja, dispunha de parte do tempo para utilizá-lo em benefício próprio. Por outro lado, o fato de ser livre por direito, estando em condições de denunciar a situação em que se encontrava, provavelmente inibiu o seu "senhor" de utilizar meios violentos de coerção contra Manoel.

Em sua luta contra a opressão social que caracterizou o escravismo, o negro vislumbrou diversas formas de afirmação de sua individualidade, que vão desde a fuga até o suicídio, passando pelo infanticídio, crimes praticados contra o senhor ou seus familiares, o aborto, o infanticídio. Também foram freqüentes as tentativas de soluções coletivas, como rebeliões e o aquilombamento. $O$ caso de Manoel caracteriza uma tentativa de acomodação com a classe senhorial, numa elaboração de soluções próprias, individuais.

É difícil quantificar e dizer a exata significação social de tentativas de acomodação como esta do africano Manoel, em virtude da escassez dos relatos. Em nosso entender, essa escassez de relatos não reflete a realidade. Ocorre que, por não haver nestes casos um conflito aberto, e sim uma tentativa de harmonização, não havia razão para a instauração de inquéritos ou para a menção em jornais.

Em contrapartida à historiografia oficial, que continua alimentando o mito da "democracia racial", que tem como alicerce a idéia de que as relações entre senhores e escravos teriam sido harmônicas, fechando os olhos para a difícil situação dos descendentes de africanos no Brasil contemporâneo, uma série de estudos vêm resgatando a resistência empreendida pelos escravos contra o domínio senhorial, encarando o negro como sujeito histórico atuante.

O que desejamos destacar com este artigo é que a resistência empreendida pelos escravos nem sempre se fez por meios violentos, sendo freqüentes os casos em que o senhor e escravo "negociaram" um acordo que satisfizesse ambas as partes. Do caso concreto do africano Manoel e do capitão Paula não teria ficado nenhum registro caso este último não tivesse quebrado o acordo, na tentativa de perpetuar a escravização de Manoel. 


\section{Notas}

1. O censo de 1872 nos revela que apenas um escravo, em cada grupo de mil, era alfabetizado. Cf. CONRAD, Robert. Os últimos anos da escravatura no Brasil (1850-1888). Rio de Janeiro, Civilização Brasileira, 1975. p.358.

2. POLÍCIA. Subdelegacia de Polícia. Maço 11. São Leopoldo, 1861. Arquivo Histórico do Rio Grande do Sul. [manuscrito]

3. A lei Eusébio de Queiróz, de $04 / 09 / 1850$, estabelecia medidas para a repressão ao tráfico de negros da África para o Brasil, considerando livre todos os africanos introduzidos a partir de então no país. cf. NEQUETE, Lenine. Escravo na jurisprudência brasileira. Porto Alegre, Revista de Jurisprudência, 1988. p.300.

4. O litoral do Rio Grande do Sul foi palco de inúmeros desembarques ilegais de africanos, como atesta a carta do Chefe de Policia para o Presidente da Província, datada de 09/10/1862. Cf. POLÍCIA. Secretaria de Polícia. Maço 4, 1862. [manuscrito]

5. POLÍCIA. Subdelegacia de Polícia. Maço 11. São Leopoldo, 1861. AHRS.

6. Ibidem.

7. Ibidem.

8. Ibidem.

9. Ibidem.

10. Ibidem.

11. CONRAD. Op. cit. p.334.

12. SANTOS, Wanderley Guilherme dos. Cidadania e Justiça. Rio de Janeiro, Campus, 1979. p.18.

13. CONRAD. Op. cit. p.60.

14. Sobre este assunto ver, entre outras, as seguintes obras: BAKOS, Margaret. RS: Escravismo \& Abolição. Porto Alegre, Mercado Aberto, 1982; GEBARA, Ademir. O Mercado de Trabalho Livre no Brasil. São Paulo, Brasiliense, 1986; KOWARICK, Lúcio. Trabalho e Vadiagem. A origem do trabalho livre no Brasil. São Paulo, Brasiliense, 1987; PESAVENTO, Sandra. Emergência dos Subalternos. Porto Alegre, Editora da Universidade/UFRGS, 1989.

15. BAKOS. Op. cit. p.28.

16. LEITMAN, Spencer. "Negros Farrapos: hipocrisia racial". In: DACANAL, José H. (org.). A Revolução Farroupilha. História \& interpretação. Porto Alegre, Mercado Aberto, 1985.

17. Sobre este assunto ver: CUNHA, Manuela Carneiro da. Os Escravos Libertos e sua Volta à África. São Paulo, Brasiliense, 1985.

18. COSTA, Emilia Viotti da. Da Senzala à Colonia. São Paulo, Difel, 1966.

19. NEQUETE. Op. cit. p.300.

20. Ibidem.

21. Manoel disse ter deixado na fazenda de Paula "hum cavallo zaino malacara, hum par de arreios, roupa de vestir, ceis galinhas, um gallo e dous frangos, meia quarta de feijão de planta [...]". POLÍCIA. Subdelegacia de Polícia. Maço 11. São Leopoldo, 1861. AHRS. 